\title{
Effect of phototherapy with turquoise vs. blue LED light of equal irradiance in jaundiced neonates
}

\author{
Finn Ebbesen ${ }^{1,2}$, Pernille K Vandborg' ${ }^{1}$, Poul H Madsen ${ }^{3}$, Torleif Trydal ${ }^{3}$, Lasse H Jakobsen ${ }^{4}$ and Hendrik J Vreman ${ }^{5}$
}

BACKGROUND: Blue light with peak emission around $460 \mathrm{~nm}$ is the preferred treatment of neonatal hyperbilirubinemia. However, studies using fluorescent light tubes have suggested that turquoise light with peak emission at $490 \mathrm{~nm}$ may be more efficient. At present, the predominant light source for phototherapy is light emitting diodes (LEDs). Hence, the aim of this study was to compare the bilirubin-reducing effect in jaundiced neonates treated either with turquoise or with blue LED light with peak emission at 497 or $459 \mathrm{~nm}$, respectively, with equal irradiance on the infants.

METHODS: Infants with gestational age $\geq 33$ wk and uncomplicated hyperbilirubinemia were randomized to either turquoise or blue LED light and were treated for $24 \mathrm{~h}$. The mean irradiance footprint at skin level was $5.2 \times 10^{15}$ and $5.1 \times 10^{15}$ photons $/ \mathrm{cm}^{2} / \mathrm{s}$, respectively.

RESULTS: Forty-six infants received turquoise light and 45 received blue light. The median (95\% confidence interval) decrease of total serum bilirubin was $35.3 \%(32.5 ; 37.3)$ and $33.1 \%(27.1 ; 36.8)$ for infants treated with turquoise and blue lights, respectively. The difference was nonsignificant $(P=0.53)$. The decrease was positively correlated to postnatal age and negatively to birth weight.

CONCLUSION: Using LED light of equal irradiance, turquoise and blue lights had equal bilirubin-reducing effect on hyperbilirubinemia of neonates.

$J_{\text {fick }}$ aundice occurs in the majority of term neonates during the first week of life and is generally harmless. In rare infants, the condition progresses into acute bilirubin encephalopathy. Deposition of unconjugated bilirubin in the central nervous system may cause serious neurodevelopmental impairment (kernicterus).

Due to its efficacy and safety, phototherapy is the treatment of choice for jaundice. The decrease in total serum bilirubin (TSB) is the result of light absorption by bilirubin in the skin which transforms the native toxic, nonpolar Z,Z-bilirubin into more excretable polar photoisomers: the configurational isomers Z,E- and E,Z-bilirubin and the structural isomers Z- and E-lumirubin (1).
Blue light with an emission peak of about $460 \mathrm{~nm}$, matching the absorption spectrum of a bilirubin-albumin solution in vitro, is routine treatment for hyperbilirubinemia worldwide as it is considered to be the most effective (2). This practice is, among others, based on the results of Cremer et al.'s original clinical study (3) and of in vitro experiments $(4,5)$. Based on a skin optical model, Agati et al. (6) predicted that the greatest effect of phototherapy would be in the spectral range $495 \pm 10 \mathrm{~nm}$. Therefore, we previously compared the bilirubinreducing effect of turquoise vs. blue fluorescent light with peak emission at 490 and $452 \mathrm{~nm}$, respectively, with equal spectral irradiance on preterm infants. We found the turquoise light to be $20 \%$ more efficient than the blue light (7).

The efficacy of phototherapy is defined in terms of the spectral quality of the light, the irradiance level, the exposed body surface area, and the duration of exposure (8).

For several years, it has been desirable to perform clinical studies to more precisely define the wavelengths which promote the greatest rate of bilirubin clearance relative to the irradiance $(6,8-10)$. Thus, potential side effects might be minimized as much as possible, especially in extremely-lowbirth-weight infants, whose thin and immature skin readily transmits light. Phototherapy of long duration, but normal irradiance, has been associated with an increased mortality among such infants (11).

Presently, light emitting diodes (LEDs) are replacing fluorescent tubes as phototherapy light sources. Their emission spectrum is narrower (i.e., they produce less unnecessary wavelengths), their irradiance decreases more slowly, and they generate less heat.

Therefore, the aim of this randomized, controlled, nonblinded study was to compare the bilirubin-reducing rate of turquoise $(497 \mathrm{~nm})$ and blue $(459 \mathrm{~nm})$ LEDs in hyperbilirubinemic neonates exposed to an equal irradiance for $24 \mathrm{~h}$.

\section{RESULTS}

Clinical and demographic data are shown in Table 1. The median decrease of TSB was 35.3\% (32.5, 37.3; 95\% confidence interval) and $33.1 \%(27.1,36.8 ; 95 \%$ confidence interval) for infants treated with turquoise and blue lights, respectively. 
Table 1 Clinical and demographic data of the infants randomized to either turquoise or blue light

\begin{tabular}{|c|c|c|}
\hline & Turquoise & Blue \\
\hline Infants, $n$ & 46 & 45 \\
\hline Gender female/male & $13 / 33$ & $16 / 29$ \\
\hline Birth weight, $g$ (median, range) & $3,240(1,915 ; 4,450)$ & $3,400(1,940 ; 4,550)$ \\
\hline Non-Caucasian, $n(\%)$ & $2(4)$ & $2(4)$ \\
\hline Weight change from birth to phototherapy, \% (median, range) & $-4.9(-9.3 ; 2.2)$ & $-4.7(-11.2 ; 8.2)$ \\
\hline Age at phototherapy, h (median, range) & $74(38 ; 179)$ & $85(38 ; 334)$ \\
\hline Weight change during phototherapy, $\%$ (median, range) & $0.5(-2.2 ; 4.4)$ & $0.9(-3.1 ; 8.6)$ \\
\hline \multicolumn{3}{|l|}{ Feeding during phototherapy } \\
\hline Infant formula $\mathrm{ml} / \mathrm{kg}$ (median, range) $)^{\frac{a}{a}}$ & $0(0 ; 144)$ & $26(0 ; 139)$ \\
\hline
\end{tabular}

Three values of feeding were missing in the turquoise group. Therefore, the percentages include 43 infants.

There was no significant difference in $\left[\Delta \mathrm{TSB}_{0-24}(\%)\right]$ between the two groups, measured either in $\mu \mathrm{mol} / \mathrm{l}(P=1.00)$ or in percentage $(P=0.53)$ (Table 2 and Figure 1). Furthermore, by adjusting for potential confounding variables, no statistical difference was found between turquoise and blue lights on the bilirubin-reducing effect (Table 3 ).

$\left[\Delta \mathrm{TSB}_{0-24}(\%)\right]$ was significantly positively associated to the postnatal age and negatively to birth weight and gestational age. However, in the multivariate analysis, gestational age was no longer significant due to its correlation to birth weight. No significant associations were demonstrated between $\left[\Delta \mathrm{TSB}_{0-24}\right.$ (\%)] and $\mathrm{TSB}_{0}$ and infant formula (Table 3).

The average body weight gain during the treatment was $0.7 \%$ (Table 1) and was not significantly associated with the light source $(P=0.32)$. The only side effect observed during the treatments was loose stool, and no cases of hypothermia were observed.

\section{DISCUSSION}

The aim of the study was to determine what wavelength range (color) of light is most effective toward decreasing TSB in the blood: turquoise light with peak emission at $497 \mathrm{~nm}$ or blue light with peak emission at $459 \mathrm{~nm}$. Besides wavelength, the irradiance of the light delivered to the infants' skin is a crucial factor, which must be controlled for when comparing the efficacy of the light. Thus, we needed to keep the irradiance of the two light sources equal. The irradiance level was normalized through adjustment of the distance between the lamp and the infants' skin level. Usually, the irradiance is measured as $\mu \mathrm{W} /$ $\mathrm{cm}^{2}$ or $\mu \mathrm{W} / \mathrm{cm}^{2} / \mathrm{nm}$ using handheld radiometers such as neoBLUE or BiliBlanket Meter II. However, because photons of different wavelength ( 497 vs. $459 \mathrm{~nm}$ ) have different energy levels, we decided that normalizing the irradiance on the basis of photons would provide a most appropriate basis for comparison of
Table 2 Changes in total serum bilirubin (TSB) during $24 \mathrm{~h}$ of phototherapy in response to light source

\begin{tabular}{|c|c|c|c|}
\hline & Turquoise & Blue & $P$ value \\
\hline Infants, $n$ & 46 & 45 & \\
\hline $\begin{array}{l}\mathrm{TSB}_{0,} \mu \mathrm{mol} / \mathrm{l} \\
(\text { median }(95 \% \mathrm{Cl}))\end{array}$ & $250(235 ; 265)$ & $260(240 ; 275)$ & 1.00 \\
\hline $\begin{array}{l}\mathrm{TSB}_{24}, \mu \mathrm{mol} / \mathrm{l} \text { (median } \\
(95 \% \mathrm{Cl}))\end{array}$ & $168(158 ; 183)$ & $178(162 ; 185)$ & 0.21 \\
\hline $\begin{array}{l}\Delta \mathrm{TSB}_{0-24^{\prime}} \mu \mathrm{mol} / \mathrm{I} \\
(\text { median }(95 \% \mathrm{Cl}) \text { ) }\end{array}$ & $83(77 ; 95)$ & $85(64 ; 95)$ & 1.00 \\
\hline $\begin{array}{l}\Delta \mathrm{TSB}_{0-24}{ }^{\prime} \% \\
\text { (median }(95 \% \mathrm{Cl}))\end{array}$ & $35.3(32.5 ; 37.3)$ & $33.1(27.1 ; 36.8)$ & 0.53 \\
\hline
\end{tabular}

the efficacy of phototherapy of the two wavelengths. The level of irradiance was chosen to reflect the irradiance of blue light delivered to neonates during phototherapy as recommended by the American Academy of Pediatrics guidelines (2). This irradiance level of $30 \mu \mathrm{W} / \mathrm{cm}^{2} / \mathrm{nm}$ was measured with a neoBLUE radiometer at a distance of $29 \mathrm{~cm}$ between lamp and skin. This radiometer is being routinely used in our neonatal intensive care unit. For this reason, we treated the neonates with an irradiance of $5.2 \pm 0.1 \times 10^{15}$ photons $/ \mathrm{cm}^{2} / \mathrm{s}$ of each of the two colors of light. Given that photons at $497 \mathrm{~nm}$ have a slightly lower energy than photons at $459 \mathrm{~nm}$ (8\%, calculated from Planck's equation), it is worth noting that normalizing irradiance on the basis of photons resulted in a relative small difference in irradiance measured on the basis of $\mu \mathrm{W} / \mathrm{cm}^{2}$ (Table 4).

There were no significant differences between the rates of decrease of TSB through use of turquoise LEDs with peak emission at $497 \mathrm{~nm}$ and blue LEDs with peak emission at $459 \mathrm{~nm}$ with an equal light irradiance delivered to the infants. 


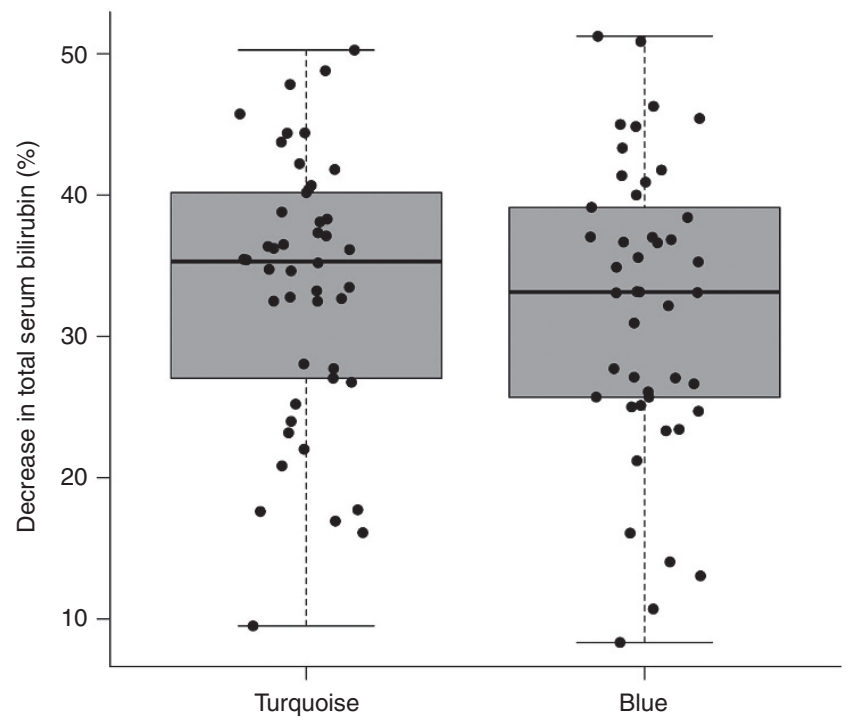

Figure 1 Box plot showing medians, 25-75 percentiles, and ranges of the decrease in total serum bilirubin $\left[\Delta \mathrm{TSB}_{0-24}(\%)\right]$ for infants treated for $24 \mathrm{~h}$ with either turquoise $(n=46)$ or blue light $(n=45)$.

Table 3 Simple linear regressions with the percentage decrease of total serum bilirubin $\left[\Delta \mathrm{TSB}_{0-24}(\%)\right]$ as response and the light source, $\mathrm{TSB}_{0}$ gestational age, birth weight, postnatal age, and infant formula as explanatory variables (each explanatory variable was then included in a multiple linear model with the same response)

\begin{tabular}{|c|c|c|c|c|}
\hline & \multicolumn{2}{|c|}{ Simple linear regression } & \multicolumn{2}{|c|}{ Multiple linear model } \\
\hline & Coefficient $(95 \% \mathrm{Cl})$ & $\begin{array}{c}P \\
\text { value }\end{array}$ & Coefficient $(95 \% \mathrm{Cl})$ & $\begin{array}{c}P \\
\text { value }\end{array}$ \\
\hline $\begin{array}{l}\text { Turquoise } \\
\text { light }\end{array}$ & $1.38(-2.75 ; 5.51)$ & 0.52 & $2.23(-1.75 ; 6.20)$ & 0.27 \\
\hline $\mathrm{TSB}_{0^{\prime}} \mu \mathrm{mol} / \mathrm{I}$ & $0.01(-0.04 ; 0.06)$ & 0.63 & $0.05(0.00 ; 0.10)$ & 0.06 \\
\hline $\begin{array}{l}\text { Gestational } \\
\text { age, d }\end{array}$ & $-0.19(-0.33 ;-0.04)$ & 0.01 & $0.03(-0.20 ; 0.25)$ & 0.82 \\
\hline $\begin{array}{l}\text { Birth } \\
\text { weight, } \mathrm{kg}\end{array}$ & $-5.06(-7.91 ;-2.20)$ & $<0.01$ & $-5.94(-10.45 ;-1.43)$ & 0.01 \\
\hline $\begin{array}{l}\text { Postnatal } \\
\text { age, h }\end{array}$ & $0.07(0.03,0.11)$ & $<0.01$ & $0.05(0.01 ; 0.09)$ & 0.02 \\
\hline $\begin{array}{l}\text { Infant formula, } \\
\mathrm{ml} / \mathrm{kg}\end{array}$ & $-0.02(-0.07 ; 0.04)$ & 0.56 & $0.01(-0.04 ; 0.07)$ & 0.58 \\
\hline
\end{tabular}

This analysis included 88 infants. Three values of infant feeding were missing. $\mathrm{Cl}$, confidence interval.

Thus, with respect to effectiveness, the turquoise light had no advantage over the blue light. However, potential side effects may be less serious in phototherapy with longer wavelengths: in cell cultures containing bilirubin, turquoise light caused less DNA damage (12) and was less cytotoxic (13), compared with blue light. Furthermore, during phototherapy with blue light, the serum level of riboflavin decreased due to photodecomposition (14).

Even though phototherapy has been used for more than 50 y (3), the most efficient light emission spectrum is still not known for certain. Presumably, the main reasons are that (i) the results from photoexposure of bilirubin-albumin solutions/
Table 4 Characteristics of the turquoise and blue LEDs

\begin{tabular}{lcc}
\hline & Turquoise & Blue \\
\hline Emission & & \\
Range $(\mathrm{nm})$ & $450-575$ & $416-524$ \\
Peak $(\mathrm{nm})$ & 497 & 459 \\
Bandwith $(\mathrm{nm})^{\mathrm{a}}$ & $484-511$ & $449-469$ \\
Angle $\left({ }^{\circ} \mathrm{C}\right)^{\mathrm{b}}$ & 60 & 60 \\
Distance $(\mathrm{cm})^{\mathrm{c}}$ & 23 & 29 \\
Irradiance & & \\
Ocean Optics & & \\
Photons/cm $/ \mathrm{s}$ & $5.2 \times 10^{15}$ & $5.1 \times 10^{15}$ \\
$\mu \mathrm{W} / \mathrm{cm}^{2, \mathrm{~d}}$ & 2,200 & 2,410 \\
neoBLUE & & 30.0 \\
$\mu \mathrm{W} / \mathrm{cm}^{2} / \mathrm{nm}^{\mathrm{d}}$ & $\mathrm{ND}^{\mathrm{a}}$ & \\
BiliBlanket Meter II & & 29.5 \\
$\mu \mathrm{W} / \mathrm{cm}^{2} / \mathrm{nm}^{\mathrm{d}}$ & $\mathrm{ND}^{\mathrm{e}}$ & \\
\hline
\end{tabular}

aAt half peak level. 'Light emission angle of LED. cDistance from lamp to belly skin ( $8 \mathrm{~cm}$ above mattress level). ${ }^{\mathrm{d}} \mathrm{Clinically,}$, the irradiance is quantified either as $\mu \mathrm{W} /$ $\mathrm{cm}^{2}$ (total energy of the spectrum) or as $\mu \mathrm{W} / \mathrm{cm}^{2} / \mathrm{nm}$ (energy per wavelength). e $\mathrm{ND}$, not determined as the radiometer was not suitable for quantifying the emission wavelength range.

plasma in vitro have been extrapolated to the clinical use on neonates, (ii) the routine blue light treatment is effective, and until recently, no substantial side effects were observed (11), and (iii) clinical studies comparing different light sources are difficult to perform as the irradiance, exposed body surface area, and exposure time all must be equal in the groups, and the irradiance must be measured by a radiometer with constant sensitivity across the entire emission range of the light sources used, which none of the handheld clinical radiometers can accomplish. The first clinical studies fulfilling these criteria are to our knowledge our previous (7) and the present studies.

Seidman et al. (15) compared the efficacy of blue LED light with peak emission at $459 \mathrm{~nm}$ with turquoise light with peak emission at $505 \mathrm{~nm}$ both with an irradiance on the infants in the range $5-8 \mu \mathrm{W} / \mathrm{cm}^{2} / \mathrm{nm}$ and found the same efficacy of the two light sources. But the irradiance of both light sources was measured by a radiometer with peak sensitivity at $450 \mathrm{~nm}$, whereby the irradiance of the turquoise light was highly underestimated.

By using a skin optical model and taking into account the present knowledge of bilirubin photochemistry, Lamola et al. (9), after initiation of our study, have published a paper suggesting that light with an emission spectrum with peak at $475-480 \mathrm{~nm}$ would be expected to have the greatest bilirubinreducing rate in neonates. Therefore, by combining the theoretical calculations by Agati et al (6) and Lamola et al (9), and our previous (7) and present clinical data, we suggest that the most efficient bilirubin-reducing light emission spectrum might be a spectrum with peak emission in the range $475-490 \mathrm{~nm}$.

The different results obtained in this study in relation to our previous one may be explained by (i) use of different light sources (LED tubes vs. broader spectrum fluorescent light tubes), (ii) the fact that the peak emission wavelength of the 
blue LED device was shifted toward longer wavelengths (452$459 \mathrm{~nm}$ ), whereby it might be more efficient in the present study $(6,16)$ and (iii) in our previous study, we compared turquoise and blue lights with equal irradiance expressed as $\mu \mathrm{W} /$ $\mathrm{cm}^{2} / \mathrm{nm}$, measured by a broadband photodiode power meter (model 460; EG\&G, Salem, MA).

The rate of decline of TSB was of the same magnitude as observed in other phototherapy studies using blue LEDs (17). The decrease of serum bilirubin is dependent on biologic diversity among the individuals and on the treatment. A few infants had only a modest $\left[\Delta \mathrm{TSB}_{0-24}(\%)\right]$ (Figure 1 ), and the reason might be multifactorial, which was not explored further in this study.

Of the other parameters determined, $\left[\Delta \mathrm{TSB}_{0-24}(\%)\right]$ was negatively correlated to birth weight. As the weight increases, the exposed body surface area in relation to weight decreases, and the skin becomes thicker and more mature, which might reduce the effect of the light.

$\left[\Delta \mathrm{TSB}_{0-24}(\%)\right]$ was positively associated to the postnatal age. With increasing age, the normal bilirubin excretion pathway matures and spontaneous accumulation of bilirubin decreases.

Contrary to phototherapy with fluorescent light, LED light therapy does not cause significant transepidermal water loss, because LEDs emit significantly less infrared radiation (18). During routine care of the infants, the average weight gain was $0.7 \%$, independent of light source.

Half of the breastfed infants were supplemented with formula due to suspicion that they did not receive enough breast milk, but the volumes were most often small. This supplementation did not enhance $\left[\Delta \mathrm{TSB}_{0-24}(\%)\right]$, perhaps because of the small volumes. That formula supplementation can enhance the decline of TSB during phototherapy as has previously been reported (19).

The strengths of the study were the use of LEDs (the phototherapy light source of the future), that the light irradiance was measured by a radiometer with a constant spectral sensitivity, and that the patient population was homogeneous.

\section{Conclusion}

Using LEDs with equal light irradiance on the infants, turquoise light with peak emission at $497 \mathrm{~nm}$ and blue light with peak emission at $459 \mathrm{~nm}$ had equal bilirubin-reducing effect in treatment of jaundiced neonates.

\section{Perspectives}

More clinical studies are needed to determine which LED lamp emission spectrum has the greatest bilirubin-reducing effect. Very likely, the peak of such a spectrum should be in the spectral range $475-490 \mathrm{~nm}$. It is needed toward optimization of future phototherapy devices to be used in the management of newborn hyperbilirubinemia. So there may still be room for improvement of the phototherapy in neonates.

\section{METHODS}

\section{Subjects}

The infants were enrolled in the study at the neonatal intensive care unit at Aalborg University Hospital between the 1 January 2013 and the 31 December 2013. Inclusion criteria were healthy neonates with uncomplicated hyperbiliirubinemia, gestational age $\geq 33 \mathrm{wk}$, birth weight $\geq 1,800 \mathrm{~g}$, postnatal age $>24 \mathrm{~h}$ and $\leq 28 \mathrm{~d}$, and treatable in a bassinet. A lower limit of birth weight was set to $1,800 \mathrm{~g}$ due to a risk of hypothermia at a lower weight. The indication of phototherapy followed the regional guidelines (20). Infants with indication of intensive treatment double light or exchange transfusion were not included. The neonatologist in charge enrolled the patients and assigned them to their groups. The infants were randomized by sealed opaque envelopes to either turquoise or blue light. The randomization was balanced in blocks of 2, 4, or 6 infants.

The phototherapy device was placed above the infants. All infants were exposed naked, except for eye pads and diapers, to continuous phototherapy for $24 \mathrm{~h}$, interrupted only for feeding and nursing up to 30 min every $3 \mathrm{~h}$. A previous study has shown that with this practice, the infants are treated on an average $85 \%$ of the time (21).

With reference to a 24 -h decrease of TSB in a previous study (22), the sample size was calculated to demonstrate a $6 \%$ difference in the decrease of TSB between the groups after $24 \mathrm{~h}$ of phototherapy, a difference judged as clinically relevant. Determining a significance level of 0.05 and a power of 0.8 , the required sample size should be at least 36 infants in each group.

Hundred and four infants were eligible for the study. The parents of six infants refused participation. Thus, 98 infants were randomized, 50 infants to turquoise and 48 to blue light. Two infants in the turquoise group were withdrawn from the study: one because of a high TSB at initiation of phototherapy $\left(\mathrm{TSB}_{0}\right.$ ) and suspicion of $\mathrm{ABO}$ isohemolytic disease to be treated with double light, the other one due to communication problems with the mother. In addition, two infants were excluded: one because of liver disease, the other one due to failed blood sampling. In the blue light group, one infant was withdrawn from the study, because of a high $\mathrm{TSB}_{0}$ and suspicion of $\mathrm{ABO}$ isohemolytic disease, and two infants were excluded due to failed blood sampling. Thus, 46 infants receiving turquoise light and 45 infants receiving blue light were included in the study.

\section{Measurements}

TSB in serum from capillary blood drawn by heel prick at initiation of phototherapy and after $24 \mathrm{~h}$ of treatment $\left(\mathrm{TSB}_{24}\right)$ was determined with the diazo-method using Cobas 8000 (Roche Diagnostics International, Mannheim, Germany) (23). The imprecision expressed as coefficient of variation was 3.0 and $1.4 \%$ at TSB levels of 176 and $333 \mu \mathrm{mol} / 1$, respectively. External quality assessment showed a bias of less than $5 \%$ in the interval $10-1,000 \mu \mathrm{mol} / \mathrm{l}$.

\section{Phototherapy Devices}

The phototherapy devices were produced by one of the authors (H.J.V.) and each of them consisted of an open aluminum angle fixture fitted with five T8 tubes $(60 \times 2.5 \mathrm{~cm})$ each containing nine equally spaced 3 -W LEDs. The LED tubes and an external driver $(60 \mathrm{~W})$ were supplied by Bright Light LED (Canoga Park, CA). The geometries of the two light systems were identical.

Photons are the elementary particles of light. However, not all photons are alike, because they can possess different levels of energy, depending upon their wavelength (color). For instance, blue photons of $459 \mathrm{~nm}$ have greater energy than turquoise photons of $497 \mathrm{~nm}$. Thus, exposure to each photon can result in different structure-altering responses for a particular molecule, such as bilirubin. Because we wished to determine the effect of the different colors of light on the bilirubin transformation rate in vivo, we measured the number of photons of each color and therefore of different energy (459 or $497 \mathrm{~nm}$ ). This measure of the rate of irradiance is slightly different (by the ratio of their wavelengths) than bedside measurements of irradiance in terms of total energy delivered, such as $\mu \mathrm{W} / \mathrm{cm}^{2}$ or $\mu \mathrm{W} / \mathrm{cm}^{2} / \mathrm{nm}$.

Because the photon fluence rate (irradiance) was lower of the turquoise LEDs than of the blue LEDs, the distance from the phototherapy lamps to the mattress was adjusted to $31 \mathrm{~cm}$ for the turquoise light and $37 \mathrm{~cm}$ for the blue light, so that the mean light irradiance at skin level was the same for the two groups. This means that the distance from the lamps to infant belly skin was 23 and $29 \mathrm{~cm}$ for the turquoise and blue lights, respectively. The distances between the lamps and the infants' skin were adjusted in practice with appropriately sized wood sticks. 
The flux density of photons was measured using a spectrometer (Model 2000+; Ocean Optics, Dunedin, FL), which had n constant spectral sensitivity over the range $200-1,100 \mathrm{~nm}$. The irradiance was measured $8 \mathrm{~cm}$ above mattress level corresponding to the average height over the mattress of the exposed infants' skin. The measurements were made in a light footprint measuring $28 \times 49 \mathrm{~cm}$ consisting of $4 \times 7=28$ squares of $7 \times 7 \mathrm{~cm}$. The mean irradiance of the footprint was $5.2 \times 10^{15}$ and $5.1 \times 10^{15}$ photons $/ \mathrm{cm}^{2} / \mathrm{s}$ for the turquoise and blue lights, respectively, measured at the start of the study. The range was from $3.6 \times 10^{15}$ to $5.7 \times 10^{15}$ photons $/ \mathrm{cm}^{2} / \mathrm{s}$. The irradiance did not change significantly during the study. In addition, the irradiance of the blue light was measured by handheld clinical radiometers, neoBLUE (Natus Medical, San Carlos, CA) and BiliBlanket Meter II (GE HealthCare Technologies, Waukesha, WI). The characteristics of the turquoise and blue LED light sources are shown in Table 4.

\section{Ethics}

The study was approved by the Committee for Biomedical Research Ethics, Region North Jutland, Denmark. Verbal and written informed consent was obtained from the parents. The study was registered with number NCT 02154165 in the Clinical Trial Registry.

\section{Data Analyses}

Fisher's exact test for contingency tables was used to test for significant difference in medians between the two groups. The two-by-two table was obtained by computing the overall median for the entire study group and then for each treatment group counting the number of infants with a decrease lower or higher than the overall median decrease. To calculate confidence intervals for the medians of each group, we applied an approximation relying on the quantiles of the binomial distribution as implemented in the ci.median function from the R-package asbio. To further investigate the effect of turquoise light compared with blue light, simple linear regressions were performed with $\left[\Delta \mathrm{TSB}_{0-24}(\%)\right]$ as response and the light source, TSB , gestational age, birth weight, postnatal age, and amount infant formula as explanatory variables. Each explanatory variable was then included in a multiple linear model with the same response. The assumption of normality was confirmed by a QQ-plot of the residuals. For all analyses, the statistical software program $\mathrm{R}$ (version 3.1.2) was used. The significance level was set to $\leq 0.05$.

\section{ACKNOWLEDGMENTS}

We thank Stephanie Kourula and Benjamin K Cline for technical assistance and valuable discussions. We are grateful to Rami Vardi of Bright Light LED, Inc, for technical support and donation of the LED tubes and drivers.

\section{STATEMENT OF FINANCIAL SUPPORT}

The authors perceived no conflicts of interest or financial disclosures.

Disclosure: There is no conflict of interest to disclose.

\section{REFERENCES}

1. McDonagh AF, Lightner DA. Phototherapy and the photobiology of bilirubin. Semin Liver Dis 1988;8:272-83.

2. American Academy of Pediatrics Subcommittee on Hyperbilirubinemia. Management of hyperbilirubinemia in the newborn infant 35 or more weeks of gestation. Pediatrics 2004;114:297-316.

3. Cremer RJ, Perryman PW, Richards DH. Influence of light on the hyperbilirubinaemia of infants. Lancet 1958;1:1094-7.
4. Ennever JF, McDonagh AF, Speck WT. Phototherapy for neonatal jaundice: optimal wavelengths of light. J Pediatr 1983;103:295-9.

5. Ennever JF. Blue light, green light, white light, more light: treatment of neonatal jaundice. Clin Perinatol 1990;17:467-81.

6. Agati G, Fusi F, Donzelli GP, Pratesi R. Quantum yield and skin filtering effects on the formation rate of lumirubin. J Photochem Photobiol B 1993;18:197-203.

7. Ebbesen F, Madsen P, Støvring S, Hundborg H, Agati G. Therapeutic effect of turquoise versus blue light with equal irradiance in preterm infants with jaundice. Acta Paediatr 2007;96:837-41.

8. Vreman HJ, Wong RJ, Stevenson DK. Phototherapy: current methods and future directions. Semin Perinatol 2004;28:326-33.

9. Lamola AA, Bhutani VK, Wong RJ, Stevenson DK, McDonagh AF. The effect of hematocrit on the efficacy of phototherapy for neonatal jaundice. Pediatr Res 2013;74:54-60.

10. Okada H, Masuya K, Yasuda S, et al. Developmental changes in serum halflife of (EZ)-cyclobilirubin. Early Hum Dev 2005;81:619-22.

11. Morris BH, Oh W, Tyson JE, et al.; NICHD Neonatal Research Network. Aggressive vs. conservative phototherapy for infants with extremely low birth weight. N Engl J Med 2008;359:1885-96.

12. Christensen T, Kinn G, Granli T, Amundsen I. Cells, bilirubin and light: formation of bilirubin photoproducts and cellular damage at defined wavelengths. Acta Paediatr 1994;83:7-12.

13. Roll EB, Christensen T. Formation of photoproducts and cytotoxicity of bilirubin irradiated with turquoise and blue phototherapy light. Acta Paediatr 2005;94:1448-54.

14. Gromisch DS, Lopez R, Cole HS, Cooperman JM. Light (phototherapy)induced riboflavin deficiency in the neonate. J Pediatr 1977;90: 118-22.

15. Seidman DS, Moise J, Ergaz Z, et al. A prospective randomized controlled study of phototherapy using blue and blue-green light-emitting devices, and conventional halogen-quartz phototherapy. J Perinatol 2003;23:123-7.

16. McDonagh AF, Agati G, Fusi F, Pratesi R. Quantum yields for laser photocyclization of bilirubin in the presence of human serum albumin. Dependence of quantum yield on excitation wavelength. Photochem Photobiol 1989;50:305-19.

17. Kumar P, Chawla D, Deorari A. Light-emitting diode phototherapy for unconjugated hyperbilirubinaemia in neonates. Cochrane Database Syst Rev 2011;12:1-37.

18. Bertini G, Perugi S, Elia S, Pratesi S, Dani C, Rubaltelli FF. Transepidermal water loss and cerebral hemodynamics in preterm infants: conventional versus LED phototherapy. Eur J Pediatr 2008;167:37-42.

19. Tan KL. Decreased response to phototherapy for neonatal jaundice in breast-fed infants. Arch Pediatr Adolesc Med 1998;152:1187-90.

20. Regional guidelines for management of neonatal hyperbilirubinemia. (https://pri.rn.dk/sider/16701.aspx).

21. Ebbesen F, Agati G, Pratesi R. Phototherapy with turquoise versus blue light. Arch Dis Child Fetal Neonatal Ed 2003;88:F430-1.

22. Donneborg ML, Knudsen KB, Ebbesen F. Effect of infants' position on serum bilirubin level during conventional phototherapy. Acta Paediatr 2010;99:1131-4.

23. Doumas BT, Kwok-Cheung PP, Perry BW, et al. Candidate reference method for determination of total bilirubin in serum: development and validation. Clin Chem 1985;31:1779-89. 